\title{
Effects of land use history and inoculation with Fusarium oxysporum f. sp. cucumberinum Owen on soil nematodes communities
}

\author{
J. F. HUA ${ }^{1,2,4}$, X. G. $\operatorname{LIN}^{1,2, *}$, W. S. SHEN ${ }^{1,2,3}$, R. YIN ${ }^{1,2}$, Y. Z. FENG ${ }^{1,2,4}$
}

\begin{abstract}
${ }^{1}$ State Key Laboratory of Soil and Sustainable Agriculture, Institute of Soil Science, Chinese Academy of Sciences, Nanjing 210008, China, ${ }^{*}$ E-mail: xglin@issas.ac.cn; ${ }^{2}$ Joint Open Laboratory of Soil and the Environment, Institute of Soil Science, Chinese Academy of Sciences and Hongkong Baptist University, Nanjing 210008, China; ${ }^{3}$ School of Chemistry and Environmental Science, Nanjing Normal University, Nanjing 210097, China; ${ }^{4}$ Graduate University of Chinese Academy of Sciences, Beijing 100049, China
\end{abstract}

\begin{abstract}
Summary
A pot culture experiment was carried out to study the effects of land use history and inoculation with Fusarium oxysporum f. sp. cucumberinum Owen $(F o c)$ on soil nematodes communities during the cucumber growing season in 2007. The results showed that land use history and inoculation had significant effects on the abundance and diversity of soil nematodes. Bacterivores were found to be the most dominant group in this study. Irrespective of inoculation, numbers of fungivores, plant-parasites and values of trophic diversity index (TD) and plant-parasites index (PPI) were greater in greenhouse soils $(\mathrm{GH})$ than in open field vegetable soils (OF) during the growth period of cucumber. While, the number of omnivores-predators and values of richness (SR) and maturity index (MI) presented an opposite trend. Foc inoculation had noticeable effects on numbers of plant-parasites and some taxa, such as Helicotylenchus, Epidorlaimus at flowering stage and Aphelenchus, Tobrilus at fruiting stage. Besides, inoculation significantly affected values of PPI at flowering stage and TD at fruiting stage, respectively. The faunal analysis showed that soil food web in GH was highly disturbed and in $\mathrm{OF}$ was degraded.
\end{abstract}

Keywords: soil nematodes; land use history; Fusarium oxysporum f. sp. cucumberinum Owen; greenhouse; ecological indices

\section{Introduction}

In order to yield more income and solve the difficulty and contradiction between limited agricultural land and increasing population, quite a lot of paddy and vegetable fields have been altered to plastic greenhouse in Eastern China (Lin et al., 2004). Consequently, violently disturbed soil quality is detected in greenhouse, such as acidification,

* corresponding author secondary salination, nutrition enrichment and nutrient unbalance due to intensive management, heavy fertilization and abnormal mini-climate ( $\mathrm{Li}$ et al., 1996; Liu et al., 2006; Shen et al., 2008). On the other hand, when the same crop or its related species are cultivated on the same soil successively, soil sickness expressed as a reduction in both crop yield and quality will be triggered. As Ye et al. (2004) and Shen et al. (2008) found, the number of effective microorganisms will be decreased, while the incidence of soil borne plant diseases could be promoted.

It is well known that, land use changes could result in changes in soil physico-chemical characters and shifts of microorganism communities (Lin et al., 2004). As compared with open vegetable soils, the kinds of carbon sources that could be metabolized by native microbes in plastic greenhouse soils greatly decreased, revealing that microbial diversity had decreased since land use change (Lin et al., 2004). Previous reports have concentrated mainly on soil microorganisms, and few studies have yet been carried out on the impacts of the land use change on soil fauna (Liu et al., 2006).

Among soil fauna, nematodes possess many characteristics that make them ideal as bioindicators for soil health assessment (Bongers, 1990; Yeates \& Bongers, 1999; Liang et al., 2005). They are ubiquitous and most abundant in soil and sediment environments (Ferris et al., 2001). Besides, soil nematodes feeding on bacteria and fungi play an important role in the detritus food web (Bongers, 1990; Chen \& Ferris, 2000; Berkelmans et al., 2003). Recently, many reports have shown agricultural management practice such as tillage, fertilization, pesticide application would result in disturbance and subsequent succession or recovery of the soil ecosystem which is reflected in the composition of nematode fauna (Neher, 1999; Freckman \& Ettema, 1993; Liang et al., 2005; Liu et al., 2006; Li et al., 2007). The plant-pathogenic fungi Fusarium oxysporum f. sp. cucumberinum Owen infects the roots of cucumber and 
colonizes the vascular system of the rhizome and sequentially results in wilt, which is one of the major problems in greenhouse cucumber production. Presently, a lot of studies focused on the relationship between the fungi and plant-parasites nematodes (Riedel, 1988; Akinsanmi \& Adekunle, 2003). There is little information on the soil nematode community response to the inoculation of Foc (Liu et al., 2006).

The objective of this work was to study the impacts of land use history, i.e., greenhouse soil and open field vegetable soil and inoculation with Foc on soil nematodes communities.

\section{Materials and methods}

\section{Soil preparation}

Soils were collected from an open field vegetable land (OF) and a plastic greenhouse vegetable land (GH) turned from an open field vegetable land approximately 12 years ago located in Yixing county, Jiangsu Province, East China. The area $\left(31^{\circ} 12^{\prime} \mathrm{N}, 119^{\circ} 53^{\prime} \mathrm{E}\right)$ is characterized by a subtropical monsoon climate, with an annual mean temperature of $15.7{ }^{\circ} \mathrm{C}$, annual mean precipitation of 1177 $\mathrm{mm}$, and average non-frost period of 240 days.

The soil is classified as Anthrosols according to World Reference Base for Soil Resources (IUSS Working Group WRB, 2006). Soils were passed through $7 \mathrm{~mm}$ sieve, and large stones and plant root debris were removed. Thereafter, $5 \mathrm{~kg}$ soils thoroughly mixed were filled into each plastic pot $(24 \mathrm{~cm}$ diameter and $22 \mathrm{~cm}$ depth). Some characteristics of the soils are shown in Table 1 (Shen et al., 2008). minated in autoclaved vermiculite before sowing. After emergence, seedlings were sprayed with 1/10 Hoagland's solution (Hoagland \& Arnon, 1950). Three seedlings of cucumber with two leaves were transplanted into each pot on 29 April, 2007. One was left after 10 days in order to gain plants with similar size. Each plant received $6 \times 10^{8}$ spores of FOC on 21 May, which was inoculated with a sterile micropipette all around the base of the stem. At the reproductive stage, each pot received about $100 \mathrm{ml}$ of $1 / 2$ Hoagland's solution every week until harvest. Pots were arranged in a randomized complete block design with four replicates per treatment. Plants were grown in a sunlit greenhouse with natural light.

\section{Soil sampling}

Five-core composite soil samples $(1.8 \mathrm{~cm}$ diameter, $15 \mathrm{~cm}$ deep) were taken from each pot at flowering (4 June) and fruiting stage (18 June), and the holes closed with minimum soil disturbance. Soil samples were collected in individual plastic bags, which were placed in an insulated container and taken to the laboratory. These soil samples were kept in cold storage at $4{ }^{\circ} \mathrm{C}$ in one week.

\section{Nematode extraction and identification}

Nematodes were extracted from $100 \mathrm{~g}$ fresh soil of each sample with a cotton-wool filter method (Oostenbrink, 1960; Townshend, 1963). At the same time, water content (\%) of each soil sample was determined. After $48 \mathrm{~h}$ extraction at room temperature, the total numbers of nematodes were counted, and their populations were expressed by individuals per $100 \mathrm{~g}$ dry weight soil. Then, the nema-

Table 1. Chemical characteristics of soils with different land use history

\begin{tabular}{ccccccccc}
\hline $\begin{array}{c}\text { Land use } \\
\text { history }\end{array}$ & $\begin{array}{c}\text { Total N } \\
\mathrm{g} \mathrm{kg}^{-1}\end{array}$ & $\begin{array}{c}\text { Total P } \\
\mathrm{g} \mathrm{kg}^{-1}\end{array}$ & $\begin{array}{c}\text { Total K } \\
\mathrm{g} \mathrm{kg}^{-1}\end{array}$ & $\begin{array}{c}\text { Organic C } \\
\mathrm{g} \mathrm{kg}^{-1}\end{array}$ & $\begin{array}{c}\mathrm{EC} \\
\mathrm{mS} \mathrm{cm}^{-1}\end{array}$ & $\begin{array}{c}\mathrm{NO}_{3}^{-}-\mathrm{N} \\
\mathrm{mg} \mathrm{kg}^{-1}\end{array}$ & $\begin{array}{c}\mathrm{NH}_{4}^{+}-\mathrm{N} \\
\mathrm{mg} \mathrm{kg}^{-1}\end{array}$ & $\mathrm{pH}\left(\mathrm{H}_{2} \mathrm{O}\right)$ \\
\hline GH & 3.82 & 2.08 & 12.78 & 17.82 & 1.67 & 910.46 & 17.08 & 5.20 \\
OF & 1.85 & 1.34 & 12.39 & 12.83 & 0.14 & 25.94 & 1.64 & 6.99 \\
\hline
\end{tabular}

Explanations: GH, greenhouse vegetable land; OF, open field vegetable land.

\section{Inoculum preparation}

A pathogenic isolate of Fusarium oxysporum f. sp. cucumberinum Owen (Foc), supplied by Northwest Sci-Tech University of Agriculture and Forestry, was grown for $7 \mathrm{~d}$ on potato dextrose medium at $28{ }^{\circ} \mathrm{C}$ in a black room, and filtered into sterilized beaker. The spore concentration was determined using a hemacytometer, and diluted with sterile distilled water to a final concentrations of $10^{7}$ spores $\mathrm{ml}^{-1}$.

\section{Experimental design}

The experiment was designed as a two factorial with the following factors: (a) land use history (greenhouse $(\mathrm{GH})$ and open field (OF)); (b) inoculation (non-inoculated (CK) and inoculated with Foc $(\mathrm{F})$ ). The four treatments are denoted as $\mathrm{CK}(\mathrm{GH}), \mathrm{F}(\mathrm{GH}), \mathrm{CK}(\mathrm{OF})$ and F (OF), respectively.

Seeds of the cucumber (Cucumis sativus L. cv. Jinyan No. 4) were surface-sterilized with $0.5 \% \mathrm{NaClO}$ and subsequently washed several times with distilled water and ger- todes were heat-killed for $2 \mathrm{~min}$ at $60{ }^{\circ} \mathrm{C}$ and preserved in $4 \%$ formaldehyde. Subsequently, 100 specimens per sample were selected randomly, and identified to genus level if possible. The classification of trophic groups was assigned to (i) bacterivores (BF), (ii) fungivores (FF), (iii) plantparasites (PP), (iv) omnivores-predators (OP), based on the known feeding habitats or stoma and esophageal morphology (Yeates \& Bongers, 1999). For samples in which nematode specimens were fewer than 100 individuals, all specimens were identified.

\section{Nematode ecological indices}

The characteristics of the nematode communities were described using the following indices: (1) trophic diversity (TD), TD $=1 / \sum \mathrm{P}_{\mathrm{i}}^{2}$, where $\mathrm{P}_{\mathrm{i}}$ is the proportion of the $\mathrm{i}$-th trophic group; (2) Simpson dominance index $(\lambda), \lambda=\sum \mathrm{P}_{\mathrm{i}}^{2}$, where $\mathrm{P}_{i}$ is the proportion of individuals in the $\mathrm{i}$-th taxon; (3) Shannon-Weaver index $\left(\mathrm{H}^{\prime}\right), \mathrm{H}^{\prime}=-\sum \mathrm{P}_{\mathrm{i}}\left(\ln \mathrm{P}_{\mathrm{i}}\right)$, where $\mathrm{P}_{\mathrm{i}}$ is the proportion of individuals in the $\mathrm{i}$-th taxon; (4) even- 
ness $\left(\mathrm{J}^{\prime}\right)$, which is determined from the diversity index as $\mathrm{J}^{\prime}$ $=\mathrm{H}^{\prime} / \mathrm{H}^{\prime} \max$, and $\mathrm{H}^{\prime} \max =\ln (\mathrm{S})$, where $\mathrm{S}$ is the total number of genera; (5) species richness $(\mathrm{SR}), \mathrm{SR}=(\mathrm{S}-1) / \ln (\mathrm{N})$, with $\mathrm{S}$ being the total number of genera and $\mathrm{N}$ being the number of individuals identified (Yeates \& Bongers, 1999); (6) maturity index (MI), $\mathrm{MI}=\sum \mathrm{v}(\mathrm{i}) \times f(\mathrm{i})$, where $v(\mathrm{i})$ is the c-p value of taxon $\mathrm{i}$, and $f(\mathrm{i})$ is the frequency of taxon $i$ in a sample (Bongers, 1990). Colonizers (c) and persisters (p) are the extremes on a scale from 1 to 5 , respectively; and (7) plant-parasite index (PPI), which was determined in a similar manner for plant parasitic genera (Bongers, 1990).

Nematode faunal analyses were conducted as indicators of food web structure, functioning and resource availability (Ferris et al., 2001), interpreting the structure-enrichment conditions of the food web. The enrichment index is calculated as $\mathrm{EI}=100 \times(\mathrm{e} /(\mathrm{e}+\mathrm{b}))$, where $\mathrm{e}$ is the abundance of individuals in guilds in the enrichment component weighted by their respective $k_{e}$ values, $b$ is the abundance of individuals in the basal component weighted by their $\mathrm{k}_{\mathrm{b}}$ values. The EI provides an indicator of resources available to the soil food web and the response of primary decomposers to those resources. The structural index is calculated as $\mathrm{SI}=100 \times(\mathrm{s} /(\mathrm{b}+\mathrm{s}))$, and $\mathrm{s}$ is the abundance of individuals in the structural component weighted by their $\mathrm{k}_{\mathrm{s}}$ values. A higher SI value suggests a food web with more trophic linkages (Ferris et al., 2001).

\section{Data analyses}

The effects of land use history and inoculation were analyzed by two-way analysis of variance (ANOVA), and differences at $\mathrm{P}<0.05$ were considered statistically significant. All statistical analyses were performed by SPSS 11.5.

\section{Results}

\section{Total nematodes}

The number of total nematodes ranged between 284 and 518 individuals per $100 \mathrm{~g}$ dry soil during this study, with the highest value in $\mathrm{F}(\mathrm{GH})$ treatment at flowering stage and the lowest value in $\mathrm{CK}(\mathrm{OF})$ at fruiting stage (Fig. 1).

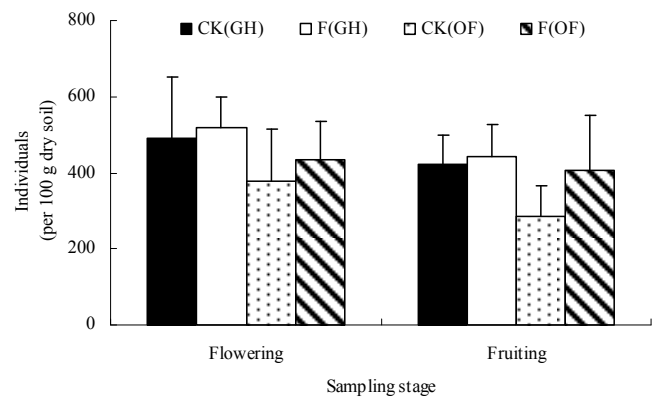

Fig. 1 The effects of land use history and inoculation on the number of total nematodes across the cucumber growth stages. GH, greenhouse vegetable land; OF, open field vegetable land; CK, control; F, inoculation with Foc. Error bars denote one standard error from the mean $(n=4)$

During the cucumber growth period, total nematode popu- lations followed the sequence of $\mathrm{F}(\mathrm{GH})>\mathrm{CK}(\mathrm{GH})>\mathrm{F}$ $(\mathrm{OF})>\mathrm{CK}(\mathrm{OF})$, and no significant land use history and inoculation effects were observed in numbers of total nematodes.

\section{Trophic groups}

Among the four trophic groups, bacterivores were found to be the most abundant group, while omnivores-predators were the least, which were even not reported in greenhouse soils with the exception of $\mathrm{F}(\mathrm{GH})$ treatment at flowering stage. No land use history and inoculation effects were found in the abundance of bacterivores. Pronounced land use history effects $(\mathrm{P}<0.05)$ were observed in the abundance of fungivores, omnivore-predators and plant-parasites at two sampling stages. Irrespective of inoculating with $F o c$, numbers of fungivores and plant-parasites were greater in greenhouse soils than in open filed soils, while the number of omnivore-predators presented an opposite trend. Besides, marked inoculation effects $(\mathrm{P}<0.05)$ were only detected in numbers of plant-parasites at flowering stage (Fig. 2).

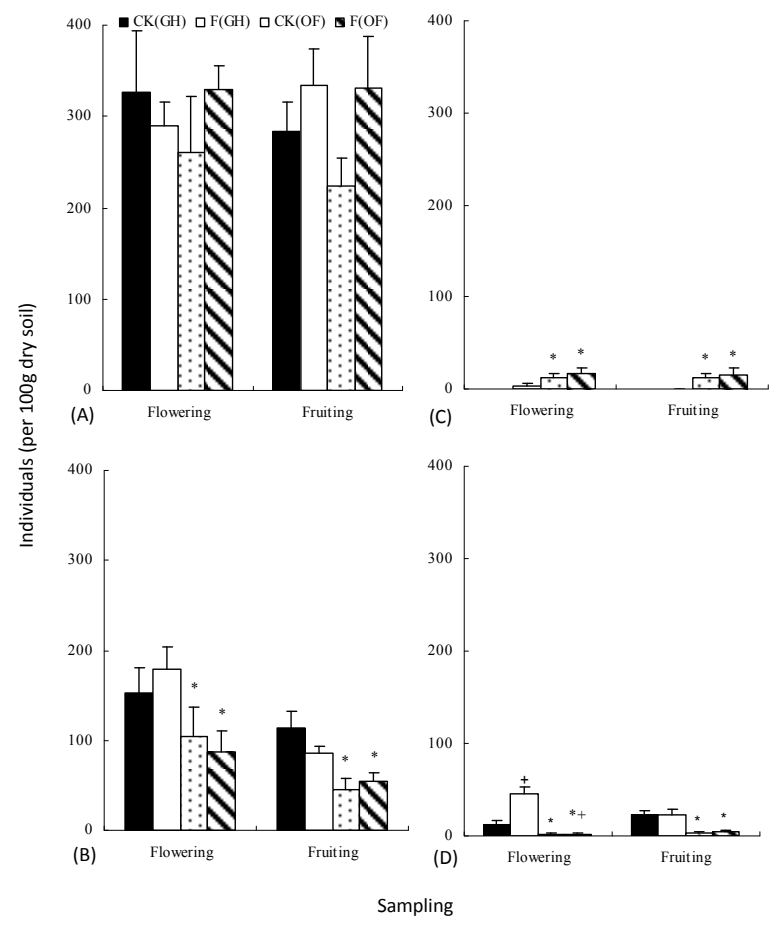

Fig. 2 The effects of land use history and inoculation on the numbers of nematode trophic groups across the cucumber growth stages. $\mathrm{GH}$, greenhouse vegetable land; $\mathrm{OF}$, open field vegetable land; $\mathrm{CK}$, control; F, inoculation with Foc. (A) bacterivores, (B) fungivores, (C) omnivore-predators, and (D) plant-parasites. Error bars denote one standard error from the mean $(n=4)$. (* Indicate significant land use history effects at $\mathrm{P}<0.05$ and + indicate significant inoculation effects at $\mathrm{P}<0.05$ at a sampling date).

\section{Nematode genera}

Overall 19 genera were recorded throughout our study, including eight bacterivores, two fungivores, seven omnivores-predators and two plant-parasites. The data on mean relative abundance (expressed as a percentage) were given in Table 2. The number of taxa discriminated was similar 
Table 2. Relative abundance (\%) of nematodes in this study. The figures are arithmetic means of duplicate samples collected on each of two sampling stages

\begin{tabular}{|c|c|c|c|c|c|c|}
\hline \multirow[t]{2}{*}{ Trophic group } & \multirow[t]{2}{*}{ Genus } & \multirow[t]{2}{*}{ C-p value } & \multicolumn{2}{|c|}{$\mathrm{GH}$} & \multicolumn{2}{|c|}{$\mathrm{OF}$} \\
\hline & & & $\mathrm{CK}$ & $\mathrm{F}$ & $\mathrm{CK}$ & $\mathrm{F}$ \\
\hline \multirow[t]{8}{*}{$\mathrm{BF}$} & Acrobeloides & 2 & 3.8 & 2.5 & $5.9^{*}$ & $7.0^{*}$ \\
\hline & Anaplectus & 2 & 0.0 & 0.0 & 0.9 & 0.9 \\
\hline & Caenorhabditis & 1 & $59.3 * *$ & $56.9^{* *}$ & 4.7 & $5.6^{*}$ \\
\hline & Cephalobus & 2 & 0.0 & 0.0 & 0.2 & 0.5 \\
\hline & Heterocephalobus & 2 & 0.8 & 0.6 & $58.6^{* *}$ & $64.1 * *$ \\
\hline & Mesorhabditis & 1 & 2.2 & $5.5^{*}$ & 1.3 & 1.3 \\
\hline & Panagrolaimus & 1 & 0.0 & 0.0 & 1.8 & 0.0 \\
\hline & Prismatolaimus & 3 & 0.3 & 0.0 & 0.0 & 0.2 \\
\hline BF total & & & 66.4 & 65.5 & 73.4 & 79.6 \\
\hline \multirow[t]{2}{*}{ FF } & Aphelenchoides & 2 & $28.4 * *$ & $26.0 * *$ & $17.4 * *$ & $8.5^{*}$ \\
\hline & Aphelenchus & 2 & 1.1 & 1.2 & 4.5 & $7.6^{*}$ \\
\hline FF total & & & 29.5 & 27.2 & 21.9 & 16.1 \\
\hline \multirow[t]{7}{*}{$\mathrm{OP}$} & Aporcelaimellus & 5 & 0.0 & 0.0 & 0.7 & 0.5 \\
\hline & Epidorylaimus & 4 & 0.0 & 0.3 & 0.1 & 0.8 \\
\hline & Eudorylaimus & 4 & 0.0 & 0.0 & 0.5 & 0.5 \\
\hline & Microdorylaimus & 4 & 0.0 & 0.0 & 0.0 & 0.3 \\
\hline & Mononchus & 4 & 0.0 & 0.0 & 0.8 & 0.6 \\
\hline & Thonus & 4 & 0.0 & 0.0 & 0.4 & 0.4 \\
\hline & Tobrilus & 3 & 0.0 & 0.0 & 1.5 & 0.5 \\
\hline OP total & & & 0.0 & 0.3 & 4.0 & 3.6 \\
\hline \multirow[t]{2}{*}{ PP } & Filenchus & 2 & 0.0 & 0.4 & 0.1 & 0.6 \\
\hline & Helicotylenchus & 3 & 4.1 & $6.6^{*}$ & 0.6 & 0.1 \\
\hline \multicolumn{3}{|l|}{ PP total } & 4.1 & 7.0 & 0.7 & 0.7 \\
\hline \multicolumn{3}{|c|}{ Number of species } & 8 & 9 & 17 & 18 \\
\hline
\end{tabular}

Explanations: BF, bacterivores; FF, fungivores; OP, omnivores-predators; PP, plant-parasites. C-p, Coloniser-persister value (Yeates \& Bongers, 1999). GH, greenhouse vegetable land; OF, open field vegetable land; CK, control; F, inoculation with Foc. Bold numbers are the total percentage of each trophic group. * Dominant genus, ** eudominant genus.

in $\mathrm{CK}(\mathrm{OF})$ and $\mathrm{F}(\mathrm{OF})$ treatments, 17 and 18 respectively. However, only 8 and 9 nematode species were observed in $\mathrm{CK}(\mathrm{GH})$ and $\mathrm{F}(\mathrm{GH})$ treatments, respectively. This result was mainly due to fewer genera of omnivores-predators in greenhouse soils. Bacterivores were found to be the most dominant trophic group, reaching 65.5 to $79.6 \%$ of the total nematode population among four treatments, followed by fungivores and plant-parasites. Omnivores-predators were least and no more than $4 \%$ (Table 2 ).

It was determined that, the presence of nematode genera in the samples with less than $1 \%$ being considered subresi- dent; $1-2 \%$ resident; $2-5 \%$ subdominant; $5-10 \%$ dominant; $10 \%$ and higher being considered eudominant (Yeates, 1970). Aphelenchoides, a known fungivores, was observed to be the dominant genus in all treatments during the study period. Bacterivores Caenorhabditis and Heterocephalobus were eudominant in $\mathrm{GH}$ and $\mathrm{OF}$ treatments, respectively. In addition, bacterivores Acrobeloides was preponderant in OF treatments (Table 2). Marked land use history effects $(\mathrm{P}<0.05)$ were observed in numbers of Aphelenchoides, Aphelenchus, Caenorhabditis, Helicotylenchus, Heterocephalobus and Tobrilus at two sampling

Table 3. Ecological indices of the nematode assemblage under control or inoculation treatment of two land use history at each sampling date $($ mean \pm S.E., $n=4)$; significance of land use history and inoculation effects, and their interaction are given

\begin{tabular}{|c|c|c|c|c|c|c|c|c|}
\hline \multirow{2}{*}{$\begin{array}{l}\text { Sampling } \\
\text { stage }\end{array}$} & \multirow{2}{*}{$\begin{array}{l}\text { Ecological } \\
\text { indices }\end{array}$} & \multicolumn{2}{|c|}{ GH } & \multicolumn{2}{|c|}{$\mathrm{OF}$} & \multirow{2}{*}{$\begin{array}{c}\text { Land use } \\
\text { history effects }\end{array}$} & \multirow{2}{*}{$\begin{array}{l}\text { Inoculation } \\
\text { effects }\end{array}$} & \multirow{2}{*}{$\begin{array}{c}\text { Interaction } \\
\text { effects }\end{array}$} \\
\hline & & CK & $\mathrm{F}$ & CK & $\mathrm{F}$ & & & \\
\hline \multirow{4}{*}{ Flowering } & $\lambda$ & $0.46 \pm 0.02$ & $0.35 \pm 0.02$ & $0.36 \pm 0.04$ & $0.40 \pm 0.05$ & ns & $\mathrm{ns}$ & ns \\
\hline & $\mathrm{J}^{\prime}$ & $0.64 \pm 0.02$ & $0.68 \pm 0.02$ & $0.64 \pm 0.03$ & $0.60 \pm 0.04$ & ns & ns & ns \\
\hline & SR & $0.61 \pm 0.07$ & $0.88 \pm 0.11$ & $1.41 \pm 0.05$ & $1.49 \pm 0.09$ & 0.000 & ns & ns \\
\hline & MI & $1.34 \pm 0.05$ & $1.30 \pm 0.04$ & $1.97 \pm 0.03$ & $2.01 \pm 0.03$ & 0.000 & $\mathrm{~ns}$ & ns \\
\hline \multirow[t]{6}{*}{ Fruiting } & TD & $1.86 \pm 0.08$ & $1.65 \pm 0.06$ & $1.53 \pm 0.05$ & $1.45 \pm 0.06$ & 0.001 & 0.034 & ns \\
\hline & $\lambda$ & $0.44 \pm 0.04$ & $0.50 \pm 0.03$ & $0.46 \pm 0.04$ & $0.50 \pm 0.03$ & ns & ns & $\mathrm{ns}$ \\
\hline & $\mathrm{H}^{\prime}$ & $1.09 \pm 0.07$ & $1.03 \pm 0.06$ & $1.23 \pm 0.10$ & $1.16 \pm 0.08$ & ns & ns & $\mathrm{ns}$ \\
\hline & $\mathrm{J}^{\prime}$ & $0.60 \pm 0.03$ & $0.56 \pm 0.03$ & $0.54 \pm 0.03$ & $0.54 \pm 0.03$ & ns & $\mathrm{ns}$ & ns \\
\hline & SR & $0.87 \pm 0.07$ & $0.87 \pm 0.05$ & $1.60 \pm 0.19$ & $1.29 \pm 0.15$ & 0.001 & ns & $\mathrm{ns}$ \\
\hline & MI & $1.27 \pm 0.07$ & $1.19 \pm 0.04$ & $1.98 \pm 0.06$ & $1.98 \pm 0.04$ & 0.000 & ns & ns \\
\hline
\end{tabular}

Explanations: TD, trophic diversity index; $\lambda$, Simpson dominance index; H', Shannon-Weaver index; J', evenness; SR, richness; MI, maturity index; PPI, plant-parasites index. GH, greenhouse vegetable land; OF, open field vegetable land; CK, control; F, inoculation with Foc. ns, non-significant. 
stages. Meanwhile, the effects of inoculating with Foc were extremely significant $(\mathrm{P}<0.05)$ on the number of Epidorlaimus, Helicotylenchus at flowering stage and Aphelenchus, Tobrilus at fruiting stage.

\section{Ecological indices}

Among the ecological indices of the nematode fauna assessed in the study, noticeable land use history and inoculation effects $(\mathrm{P}<0.05)$ were found in the values of PPI and TD at flowering and fruiting stage, respectively. While, neither land use history nor inoculation effects were detected in the values of $\lambda$ and $J^{\prime}$ across the cucumber growth stages. Significant land use history effects $(\mathrm{P}<$ $0.05)$ were observed in the values of SR and MI at two sampling stages. Their values were higher in open field than in greenhouse regardless of inoculation (Table 3 ).

The faunal profiles were constructed for four treatments at each sampling date based on the relative weighted abundance of nematode guilds. Significant land use history effects $(\mathrm{P}<0.05)$ were found in the values of both SI at fruiting stage and EI at two sampling stages. On the whole, the faunal profiles showed that the food web in greenhouse soils was disturbed, and the environment was highly disturbed, because $\mathrm{CK}(\mathrm{GH})$ and $\mathrm{F}(\mathrm{GH})$ at flowering and fruiting stages were in quadrat A (Fig. 3). In addition, the food web in open field soils was stressed, because they were in quadrat D (Fig. 3), which indicated stressed disturbance and a degraded food web condition in greenhouse.

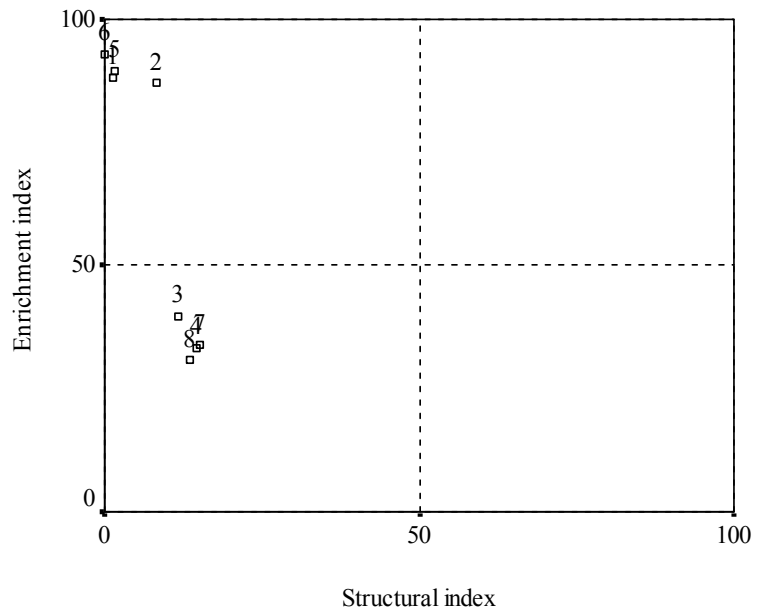

Fig. 3 The effects of land use history and inoculation on the faunal profile representing the structure and enrichment conditions of the soil food web indicated by nematodes in $\mathrm{CK}(\mathrm{GH})(1), \mathrm{F}(\mathrm{GH})(2)$, $\mathrm{CK}(\mathrm{OF})(3), \mathrm{F}(\mathrm{OF})(4)$ at flowering stage and $\mathrm{CK}(\mathrm{GH})(5), \mathrm{F}(\mathrm{GH})$ (6), $\mathrm{CK}(\mathrm{OF})(7), \mathrm{F}(\mathrm{OF})(8)$ at fruiting stage.

\section{Discussion}

\section{Land use history effects}

Plastic greenhouse can provide vegetables even in inappropriate growth seasons, and thus, yield much more income than traditional open field vegetable land. In order to obtain higher production, adding compounds to soils and crops has become a common practice, such as improving the nutrient supply in soils (organic matter and fertilizers) or crop protection and disease control (pesticides). All these practices and the artificial environment inside the greenhouse, i.e., temperature, moisture, aeration and rainfall should change soil physico-chemical characters and cause shifts of microbial and faunal communities (Lin et al., 2004; Shen et al., 2008).

In this study, bacterivores were the most abundant nematodes group. The higher population indicated that the bacterial-based energy channel contributed relatively more to organic matter decomposition (Ou et al., 2005). Irrespective of inoculation, numbers of fungivores and plant-parasites were higher in greenhouse soils than in open filed vegetable soils during the cucumber growth. This result was consistent with Liu et al. (2006), who found the population of fungivores and plant-parasites nematodes increased with the increasing of planting-year in greenhouses. Wardle \& Yeates (1993) concluded that microbivorous nematodes were limited by resource availability. Greater abundance of fungivores may result from more food resource, since the fungal amounts increased in plastic greenhouse soils as compared with open field vegetable soils (Lin et al., 2004). It is well known that, plant-parasites were associated with the production of root. In our study, the effects of land use history and inoculation were extremely significant on fresh weight and dry weight of root at the end of harvesting, with the lowest value in greenhouse soils (Shen et al., 2008). Obviously, greater number of plant-parasites in greenhouse soils mainly ascribed to the land use history. Since turned into plastic greenhouse, the land had received heavy chicken manure and synthetic fertilizers and planted vegetable even in winter for 12 years, which could dramatically increase the abundance of plant-parasites (Liu et al. 2006). Neher (1999) observed the number of plant-parasites was greater in soils managed organically than conventionally. Moreover, many publications demonstrated that plant-parasites could be controlled by vegetation types and closely related to rooting patterns (Manlay et al., 2000; Ou et al., 2005). On the other hand, higher soil nutrition condition (Table 1) in greenhouse resulting from heavy fertilization were closely associated with this result, since numbers of fungivores and plant-parasites were correlated positively with soil total organic carbon, total nitrogen and electrolytic conductivity, but negatively with soil $\mathrm{pH}(\mathrm{Ou}$ et al., 2005; Liu et al., 2006).

Maturity index (MI) had been widely used to reflect the degree of disturbance of the soil ecosystem (Bongers, 1990; Ou et al., 2005; Liu et al., 2006). It is based on the allocation of nematode taxa on the colonizer-persister scale, comparable to the r-K-continuum in the broad sense. The colonizers receiving low c-p values have high reproduction and dominant in unstable environments, while the persisters are more sensitive to pollutants and other disturbances (Bongers, 1999; Porazinska et al., 1999). Obviously fewer omnivores-predators, most of whom belonging to persisters were detected in greenhouse soil in this investigation. Freckman \& Ettema (1993) owed the low abun- 
dance and diversity of omnivores-predators to intensive agricultural practices. Meanwhile, lower values of MI were found in greenhouse soil regardless of inoculation. After the land use patterns were changed from open field to greenhouse, soil microbial activity and functional diversity decreased (Lin et al., 2004; Shen et al., 2008). As the rate regulators for the activity of microorganisms (Senapati, 1992), nematodes species diversity, richness and the detected species numbers were also reduced in greenhouse soils. On the whole, our results indicated an unstable environment in greenhouse. Excessive use of fertilizers, intensive management and the artificial environment will cause acidification, secondary salination, nutrition enrichment and nutrient unbalance in the soils (Li et al., 1996; Lin et al., 2004; Shen et al., 2008). In addition, the intensive greenhouse agricultural practices those utilize agrochemicals, have created non-point pollution of metals and organics (Kokkinaki et al., 2007). Irrespective of inoculation, values of plant-parasites index (PPI) were greater in greenhouse soils. Bongers et al. (1997) and Liu et al. (2006) reported the inverse relationship between the MI and PPI under enriched nutrient conditions, e.g. the MI decreases and PPI increases with increasing nutrient status. The obtained results in this study also showed that the values of MI and PPI were inversely related.

Since nematodes are commonly numerically predominant in soil environments, changes in their community composition can show the changes in functional structure of other soil fauna exposed to a similar disturbance (Liang et al., 2005). The faunal profiles showed that soil food web in greenhouse was highly disturbed, and that in open field was degraded. This study was in accordance with the report by Ferris et al. (2001), who concluded that food webs from annual cropping systems usually mapped in the left side of the faunal profile, and conventional agriculture was in quadrat $\mathrm{D}$ and organic agriculture was in quadrat $\mathrm{A}$. Enrichment index (EI) reflects the availability of resources to the soil food web and the response of primary decomposer to the resources (Ferris et al., 2001). Higher EI values suggested greater bacterial activity in greenhouse soils, because the application of manures and fertilizers provided sources and favorable conditions for bacterial decomposition. Greater values of structural index (SI) in the open field resulting from the presence of omnivorespredators, suggested a food web with more trophic linkages in these ecosystems (Ferris \& Matute, 2003), which potentially provided more biological control to regulate or suppress plant-parasitic nematodes (Berkelmans et al., 2003).

\section{Inoculation effects}

Soil borne plant pathogens Fusarium oxysporum f. sp. cucumerinum Owen is the cause of cucumber wilts. It can attack and finally colonize the vascular bundle system in roots. The production of cucumber in greenhouse is severely limited by Foc (Yu et al., 2000; Shen et al., 2008). Since the initial report of an interaction of a plant-parasites nematode, Meloidogyne sp. with Fusarium oxysporum on cotton in 1892, considerable interactions of plant-parasitic nematodes with the plant-pathogenic fungi have been described (Riedel, 1988; Akinsanmi \& Adekunle, 2003; Vu et al., 2006). Plant-parasites undoubtedly promote ingress of soil-borne plant pathogens into their host plant by simple, physical wounding of the host plant (Riedel, 1988). Our investigation showed significant inoculation effects on the number of plant-parasites at flowering stage. The number of plant-parasites was higher in inoculated treatments than in non-inoculated treatments regardless of land use history. Thereby, the Foc may benefit the reproduction of some nematodes, since infected roots became easier to be penetrated by plant-parasites nematodes. Additionally, the number of fungivores Aphelenchus was noticeably affected by $F o c$ at fruiting stage, and the greater number was observed in inoculated treatments. As we known, fungalfeeding nematodes are important components of the fungal decomposition pathway. They may contribute to biological control of the causal agents of some soil-borne phytopathogenic diseases through their feeding behavior (Ishibashi \& Choi, 1991; Chen \& Ferris, 2000). Chen \& Ferris (2000) found $F$. oxysporum supported significantly more nematodes than the other four fungal species in vitro. Irrespective of land use history, lower values of TD were detected in inoculated treatments, which indicated low trophic diversity and a disturbed soil environment at fruiting stage.

The obtained results indicated that, land use history and inoculating with Foc remarkably affected soil nematodes communities. Irrespective of inoculation, numbers of fungivores and plant-parasites were higher in greenhouse soils during the cucumber growth. However, the number of omnivore-predators and value of MI were lower in greenhouse soils. The faunal profiles showed the food web in greenhouse soils was highly disturbed and in open field vegetable soils was degraded. Meanwhile, effects of inoculation with Foc were significant on the number of plantparasities and some taxa, such as Helicotylenchus, Epidorlaimus at flowering stage and Aphelenchus, Tobrilus at fruiting stage. In our study, vertical factors were not considered. The nematodes communities and soil physicochemical characters exhibit a typical vertical distribution. The depth of the sampling might be responsible for some consistencies and discrepancies. Therefore, further studies are needed.

\section{Acknowledgements}

The authors are grateful to the financial support from the Knowledge Innovation Project of Chinese Academy of Sciences (No. Kzcx3-sw-439, Kzcx2-yw-408).

\section{References}

Akinsanmi, O. A., Adekunle, O. K. (2003): Effect of Fusarium oxysporum f. sp. glycines and Sclerotium rolfsii on the pathogenicity of Meloidogyne incognita race 2 to soybean. Plant Soil, 253: 429 - 435

Berkelmans, R., Ferris, H., Tenuta, M., Van Bruggen, 
A. H. C. (2003): Effects of long-term crop management on nematode trophic levels other than plant feeders disappear after 1 year of disruptive soil management. Appl. Soil Ecol., 23: 223 - 235

BONGERS, T. (1990): The maturity index: an ecological measure of environmental disturbance based on nematode species composition. Oecologia, 83: $14-19$

BONGERS, T. (1999): The Maturity Index, the evolution of nematode life history traits, adaptive radiation and cpscaling. Plant Soil, 212: 13 - 22

Bongers, T., Meulen, H., Korthals, G. (1997): Inverse relationship between the nematode maturity index and plant parasite index under enriched nutrient conditions. Appl. Soil Ecol., 6: 195 - 199

CHEN, J., FERRIS, H. (2000): Growth and nitrogen mineralization of selected fungi and fungal-feeding nematodes on sand amended with organic matter. Plant Soil, 218: 91 - 101 Ferris, H., Bongers, T., De Goede, R. G. M. (2001): A framework for soil food web diagnostics: extension of the nematode faunal analysis concept. Appl. Soil Ecol., 18: 13 $-29$

Ferris, H., MAture, M. M. (2003): Structural and functional succession in the nematode fauna of a soil food web. Appl. Soil Ecol., 23: $93-110$

Freckman, D. W., EtTema, C. H. (1993): Assessing nematode communities in agroecosystems of varying human intervention. Agric. Ecosyst. Environ., 45: 239 - 261

HoAgland, D. R., ARnON, D. I. (1950): The water-culture method for growing plants without soil. California Agric Exp Station Circular 347, University of California, Berkley, pp. 32

ISHIBASHI, N., COIH, D. R. (1991): Biological control of soil pests by mixed application of entomopathogenic and fungivorous nematodes. J. Nematol., 23: 175 - 181

IUSS Working Group WRB (2006): World reference base for soil resources 2006, World Soil Resources Reports No. 103, FAO, Rome, pp. $71-72$

KOKKINAKI, A., TZORAKI, O. A., TYROYOLA, K., NiKOLAIDIS, N. P. (2007): Mobility of copper in greenhouse soils. J. Hazard. Mater., 149: 557 - 561

LI, Q., LiAnG, W. J., JiAnG, Y., SHI, Y., ZHU, J. G., NeHER, D. A. (2007): Effect of elevated CO2 and $\mathrm{N}$ fertilization on soil nematode abundance and diversity in a wheat field. Appl. Soil Ecol., 36: 63 - 69

LI, W. Q., Du, B. H., LuO, H. Y., DinG, F. J. (1996): The influences of greenhouse cultivation on soil microflora. Soil Fertilizer, 2: $31-33$

Liang, W. J., Li, Q., Jiang, Y., Neher, D. A. (2005): Nematode faunal analysis in an aquic brown soil fertilised with slow-release urea, Northeast China. Appl. Soil Ecol., 29: $185-192$

Lin, X. G., Yin, R., Zhang, H. Y., HuAnG, J. F., Chen, R. R., CAO, Z. H. (2004): Changes of soil microbiological properties caused by land use changing from rice-wheat rotation to vegetable cultivation. Environ. Geochem. Health, 26: $119-128$

LIU, Y. J., HuA, J. F., JiANG, Y., LI, Q., WEN, D. Z. (2006): Nematode communities in greenhouse soil of different ages from Shenyang suburb. Helminthologia, 43: $51-55$

Manlay, R. J., Cadet, P., Thioulouse, J., Chotte, J. L. (2000): Relationships between abiotic and biotic soil properties during fallow periods in the Sudanian zone of Senegal. Appl. Soil Ecol., 14: 89 - 101

NeHER, D. A. (1999): Nematode communities in organically and conventionally managed agricultural soils. $J$. Nematol., 31: $142-154$

OOSTENBRINK, M. (1960): Estimating nematode populations by some selected methods. Nematology, 6: 85- 102

OU, W., LiAnG, W. J., JiAnG, Y., LI, Q., WEN, D. Z. (2005): Vertical distribution of soil nematodes under different land use types in an aquic brown soil. Pedobiologia, 49: $139-$ 148

Porazinska, D. L., DunCAN, L.W., MCSORley, R., GRAHAM, J. H. (1999): Nematode communities as indicators of status and processes of a soil ecosystem influenced by agricultural management practices. Appl. Soil Ecol., 13: $69-86$

RIEDEL, R. M. (1988): Interactions of plant-parasitic nematodes with soil-borne plant pathogens. Agriculture, Ecosystems and Environment, 24: 281 - 292

SENAPATI, B. K. (1992): Biotic interactions between soil nematodes and earthworms. Soil Biol. Biochem., 24: 1441 $-1444$

Shen, W. S., Lin, X. G., GaO, N., ZhanG, H. Y., Yin, R., SHI, W. M., DUAN, Z. Q. (2008): Land use intensification affects soil microbial populations, functional diversity and related suppressiveness of cucumber Fusarium wilt in China's Yangtze River Delta. Plant Soil, 306: 117 - 127

TownSHEND, J. L. (1963): A modification and evaluation of the apparatus for the Oostenbrink direct filter extraction method. Nematologica, 9: $106-110$

Vu, T., Hauschild, R., SikORA, R. A. (2006): Fusarium oxysporum endophytes induced systemic resistance against Radopholus similis on banana. Nematology, 8: 847 - 852

Wardle, D. A., Yeates, G. W. (1993): The dual importance of competition and predation as regulatory forces in terrestrial ecosystems: evidence from decomposer foodwebs. Oecologia, 93: $303-306$

Ye, S. F., Yu, J. Q., Peng, Y. H., ZhenG, J. H., ZoU, L. Y. (2004): Incidence of Fusarium wilt in Cucumis sativus L. is promoted by cinnamic acid, an autotoxin in root exudates. Plant Soil, 263: 143 - 150

YeATES, G. W. (1970): The diversity of soil nematode faunas. Pedobiologia, 10: $104-107$

YEATES, G.W., BONGERS, T. (1999): Nematode diversity in agroecosystems. Agric. Ecosys. Environ., 74: 113 - 135

Yu, J. Q., Shou, S. Y., Qian, Y. R., Hu, W. H. (2000): Autotoxic potential in cucurbit crops. Plant Soil, 223: 147 $-151$

ACCEPTED SEPTEMBER 26, 2008 